\title{
An Experiment on the Seismic Behavior of Reinforced Masonry Buildings with Transverse Bearing Wall
}

\author{
Hailong Dong ${ }^{1, a}$,Tiejun $\mathrm{Qu}^{1, \mathrm{~b}}$ \\ ${ }^{1}$ College of Civil Engineering, North China University of Technology, Beijing 100144, China \\ adhlzdan@163.com, ${ }^{\text {b } q u t i e j u n 18 @ 163 . c o m ~}$
}

\begin{abstract}
Keywords:Masonry structure; Aseismic strengthening; Pseudo-dynamic test; Quasi-static test Abstract.A 1:2 reduced scale ordinary masonry structure model with no seismic fortification measures was designed in this paper. After 6 degree rare earthquake, this model has been reinforced by additional concrete beams. Comparedwithresilience, displacement, acceleration and other characteristic in the case of before and after the reinforcement in 6 degrees rareof seismic action.By undertaking quasi-static test with the masonry structure after reinforcement, studied the ultimate bearing capacity, hysteretic curves, skeleton curves, stiffness degradation curve and carry out cracks, then compared with the skeleton curve in the previous studies.
\end{abstract}

\section{Introduction}

Currently, there are still a large number of ordinary masonry structure with no seismic fortification measures exists in China. It has seriously threatened the safety of people's live and properties ${ }^{[1]}$. The tensile strength, shear strength of masonry materials and the overall seismic capacity are weak. These ordinary masonry buildingswithout seismic fortification measures which seismic strengthened after earthquake can meet the requirements of the current regulations or not pending further study. Therefore, it is very necessary to make comparison of the before and after the reinforcement masonry structure' seismic behavior and do further research on seismic behavior of the masonry structure after reinforcement.

In the previous studies, the modelbuilding only set L type constructional column in the four corners which makes the ring beams and constructional columns relatively large and not conformity with the actual situation. Therefore, this experimental model designed to be a two layer four rooms, $1: 2$ reduced scale based on the dormitory building of NCUT.

\section{Model Design}

The modelwas an ordinary masonry structure with no seismic fortification measures, which is shown in Fig.1. According to the specification ${ }^{[2]}$, the plane size of the structure was $6060 \mathrm{~mm} \times 1260 \mathrm{~mm}$,open-plan was $1450 \mathrm{~mm}$ and depth was $1140 \mathrm{~mm}$, each floor height was $1690 \mathrm{~mm}$. The model was built on the reinforced concrete baseplate which connected with ground by high strength bolts.

The section size of the beam was $120 \mathrm{~mm} \times 100 \mathrm{~mm}$, set $4 \varphi 6$ rebar. According to the specification ${ }^{[3]}$ ${ }^{[4]}$, L type section was used in reinforced concrete column in the corner of wall, dimensions of long and short side was $300 \mathrm{~mm}$ and $120 \mathrm{~mm}$, longitudinal steels in ring-beam were $4 \varphi 6$ and $12 \varphi 6$ in column which were laid in two rows.No less than $0.9 \mathrm{~m}$ steel ties were settled at bottom, mid and top of each story to tie columns and walls. The size of pin key was $100 \mathrm{~mm} \times 100 \mathrm{~mm}$, connected with beam, column and wall, set $4 \varphi 6$ rebar and stirrup $2 \varphi 6,100 \mathrm{~mm}$ depth in the wall. C25 concrete used in column, beam and baseplate. Mu10 fired common brick which size was $240 \mathrm{~mm} \times 115 \mathrm{~mm} \times 53 \mathrm{~mm}$ and M7.5 cement mortar were used to build the model. The thickness of concrete precast slab was $70 \mathrm{~mm}$, and wall was $120 \mathrm{~mm}$. Reinforced masonry model is shown in Fig.2. 


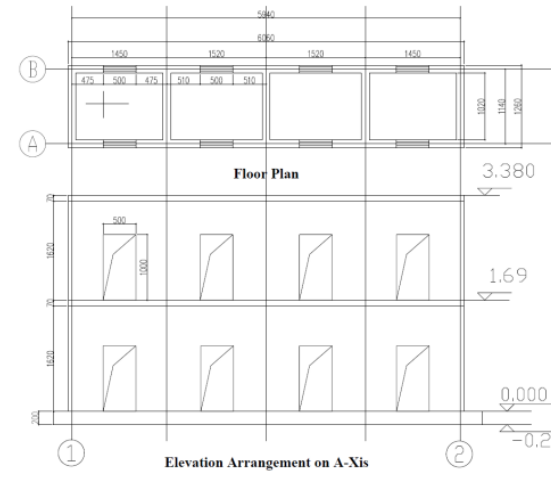

Fig.1 Masonry structure model

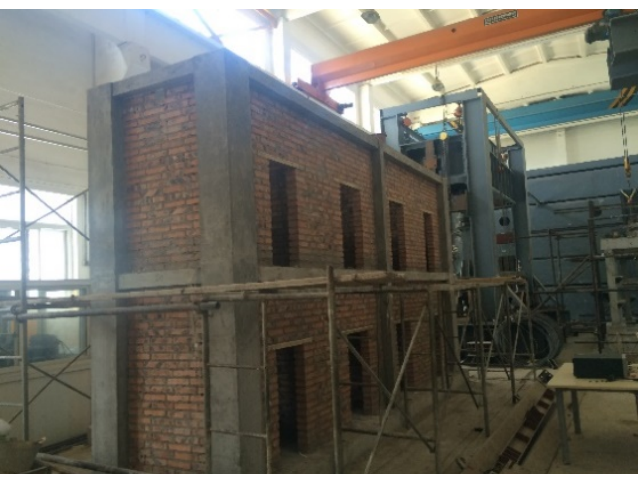

Fig.2 Reinforced masonry model

\section{Pseudo-dynamic test}

Working Condition and Seismic wave.Seismic wave shown in Fig.3 and Fig.4 was artificially synthesizedaccording to working condition of the test (site classification is II, seismic design group is group I ). Parameter used to synthetic seismic wave are shown in Table.1.

Table.1 Parameter used to synthetic seismic wave

\begin{tabular}{ccccc}
\hline $\begin{array}{c}\text { seismic } \\
\text { intensity (rare) }\end{array}$ & $\begin{array}{c}\text { peak } \\
\text { acceleration } \\
\mathrm{m} / \mathrm{s}^{2}\end{array}$ & $\begin{array}{c}\text { horizontal earthquake influence } \\
\text { coefficient } \alpha_{\max }\end{array}$ & $\begin{array}{c}\text { Eigen period } \\
\mathrm{Tg} / \mathrm{s}\end{array}$ & $\begin{array}{c}\text { time span } \\
\Delta \mathrm{t} / \mathrm{s}\end{array}$ \\
\hline 6 & 1.25 & 0.28 & 0.4 & 0.01 \\
7 & 2.20 & 0.5 & 0.4 & 0.01 \\
\hline
\end{tabular}

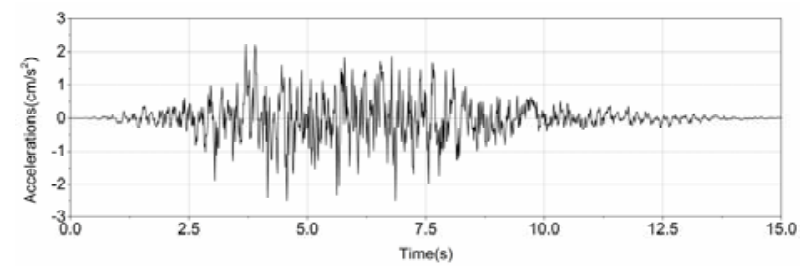

Fig.3. 6 degree rare earthquake wave

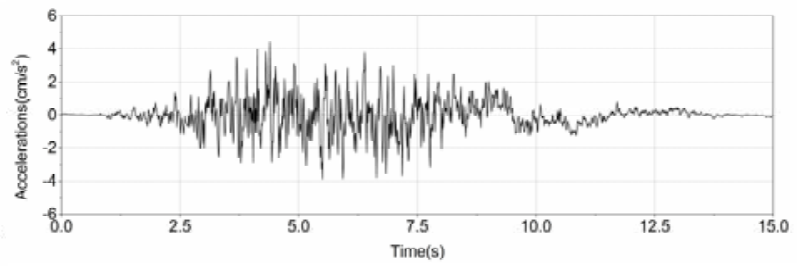

Fig.4. 7 degree rare earthquake wave

Seismic Response.The maximum value of displacement, velocity, and restoring force under the earthquake action of the model are shown in Table 2. The hysteretic curve of the structure can reflect the damage degree of the structure ${ }^{[5]}$ which is shown in Fig.5. The reinforcement ring beam and structural column improved the structural integrity and stiffness. The curve shown in linear relationship, plastic deformation is small and the structure is still in elastic stage.

Table.2 Maximumvalue of seismic response

\begin{tabular}{ccccc}
\hline reinforcement & $\begin{array}{c}\text { seismic intensity } \\
\text { (rare) }\end{array}$ & $\begin{array}{c}\text { acceleration } \\
/ \mathrm{m}^{-2}\end{array}$ & $\begin{array}{c}\text { displacement } \\
/ \mathrm{mm}\end{array}$ & $\begin{array}{c}\text { restoring force } \\
/ \mathrm{KN}\end{array}$ \\
\hline \multirow{2}{*}{ before } & \multirow{2}{*}{6} & -4.64 & -0.57 & -28.08 \\
& & 3.42 & 0.42 & 31.78 \\
\multirow{3}{*}{ after } & 6 & -4.11 & -0.51 & -36.02 \\
& & 4.22 & 0.44 & 35.69 \\
& \multirow{2}{*}{7} & -7.64 & -1.44 & -67.86 \\
& 7 & 8.27 & 1.34 & 66.40 \\
\hline
\end{tabular}




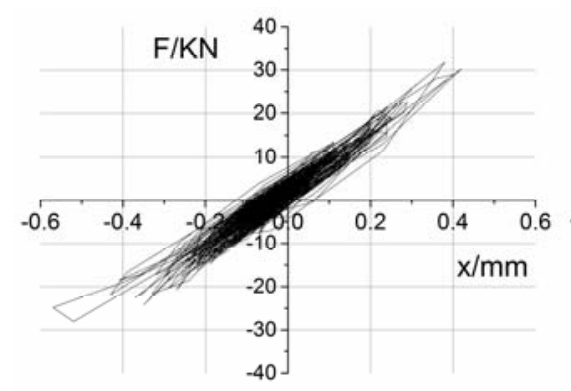

(a)

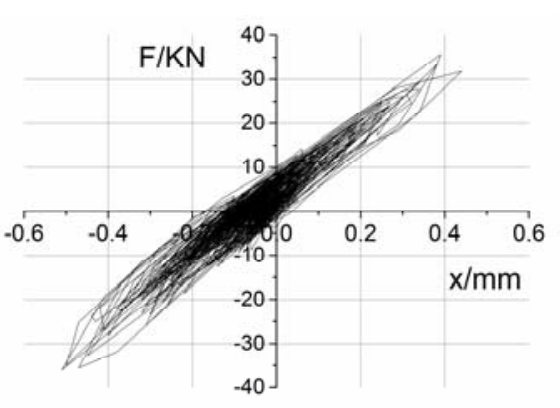

(b)

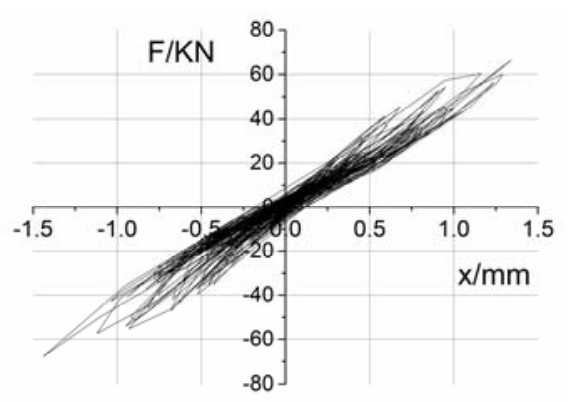

(c)

Fig.5. restoring force-displacement curve:(a) 6 degree rare earthquake of pre reinforcement (b) 6 degree rare earthquake of after reinforcement(c) 7 degree rare earthquake of after reinforcement

\section{Quasi-static test}

Track Development. One layer of wall cracked first along with the dropped off of mortar in the process of loading. The two layers of wall, beam, column joints also appeared cracks with the increaseof load, crack extension along 45 degrees at four corners of windows and doors and formed cross cracks gradually, which is shown in Fig.6. Crack distributionis shown inFig.7. After the ultimate load, the displacement increased and load began to decrease. The cracks appeared almost through the wall then the structure reachedto the limit state.

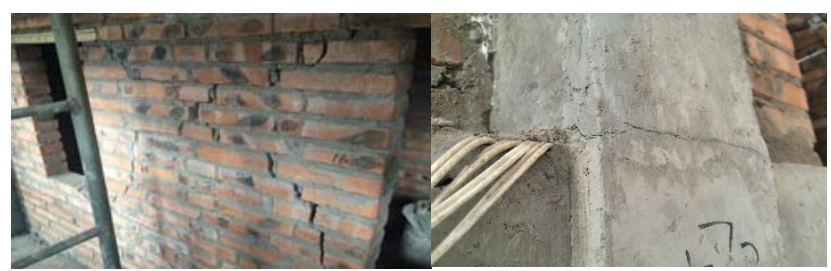

Fig.6. Crack in wall, joint of beam and column

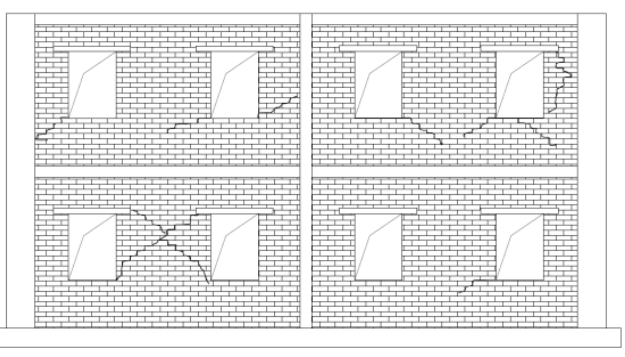

Fig.7. Crack patterns in the wall

Hysteretic Curve.Hysteretic curve of the structure is shown in Fig.8. We can see that at the beginning of loading, the restoring force-displacement curves of the structure shown in linear relationship, almost no residual deformation, and the structure was in the elastic stage. Then the curve was nonlinear, the slope decreases and relatively full with the load increased. The ultimate load is $161 \mathrm{KN}$ and the test was terminated when the displacement was close to $40 \mathrm{~mm}$.

Table.3. Eigen value of skeleton curve

\begin{tabular}{ccccccc}
\hline $\begin{array}{c}\text { structure } \\
\text { type }\end{array}$ & $\begin{array}{c}\text { load } \\
\mathrm{P}_{\mathrm{cr}} / \mathrm{KN}\end{array}$ & $\begin{array}{c}\text { displacement } \\
\mathrm{d}_{\mathrm{cr}} / \mathrm{mm}\end{array}$ & $\begin{array}{c}\text { Ultimate load } \\
\text { load }\end{array}$ & $\begin{array}{c}\text { Limit displacement } \\
\text { displacement } \\
\text { load }\end{array}$ & $\begin{array}{c}\mathrm{K} N \\
\mathrm{~d}_{\mathrm{pmax}} / \mathrm{mm}\end{array}$ & $\begin{array}{c}\mathrm{P}_{\mathrm{dmax}} / \mathrm{KN} \\
\text { displacement } \\
\mathrm{d}_{\mathrm{max}} / \mathrm{mm}\end{array}$ \\
\hline model & 80 & 2.05 & 158.7 & 25 & 138.5 & 40 \\
$\begin{array}{c}\text { Prototype } \\
\text { Pre }\end{array}$ & 320 & 4.1 & 634.8 & 50 & 554 & 80 \\
studies & 189.29 & 4 & 295 & 32.6 & 265.9 & 72.3 \\
\hline
\end{tabular}

Skeleton Curve.The skeleton curve ${ }^{[6]}$ (which is shown in Fig.9)of the modelcan reflect the characteristics of the restoring force, displacement and the ductility of the structure directly. Crack on the wall was large, the wall loss carrying capacity when the structure close to limit state. But because of the beam, constructional column, the structure still maintain good integrity, not collapsed. 


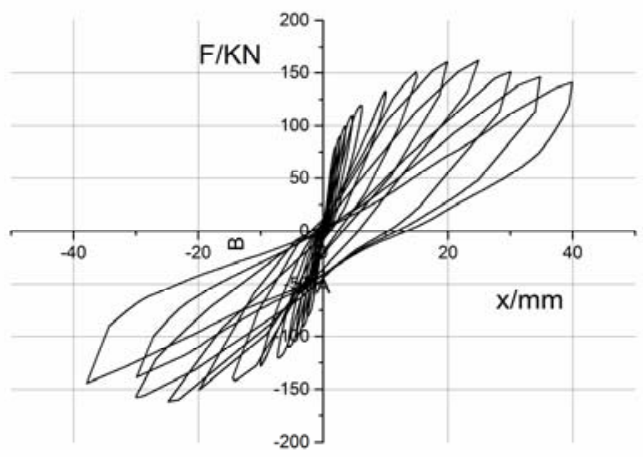

Fig.8 Hysteretic curve

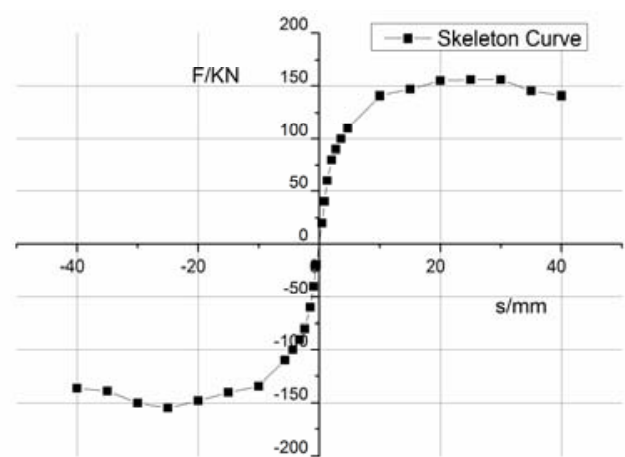

Fig.9.Skeleton curve

Hereon, compare the experiment status with previous studies ${ }^{[7]}$. The model structure in the previous studies was a two layers and single bay full-scale masonry structure which only set L type constructional column in the four corners, and that made the ring beams and constructional columns relatively large. The plane size was $2400 \mathrm{~mm} \times 3600 \mathrm{~mm}$ and the section size of the structural column was $240 \mathrm{~mm} \times 240 \mathrm{~mm}$. The skeleton curves are normalized ${ }^{[8]}$ by using non dimensional form, which is shown in Fig.10 and the eigenvalue is shown in Table.3. Structure's stiffness and restoring force of this test dropped uniformly with the increase of displacement when reached the ultimate load. But it decreased slowly in previous studies due to the large ring beam and structural column.

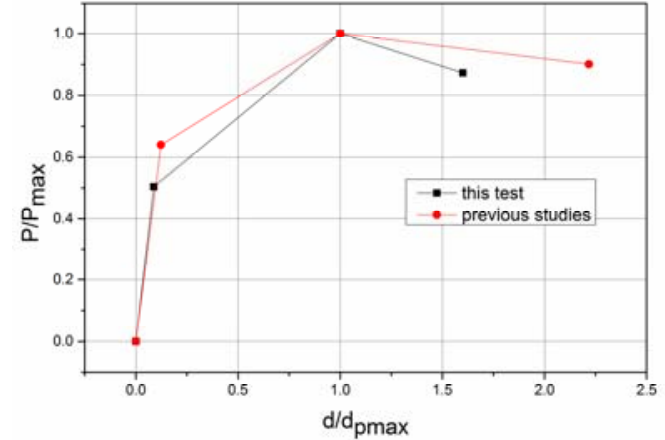

Fig.10. Normalized skeleton curves

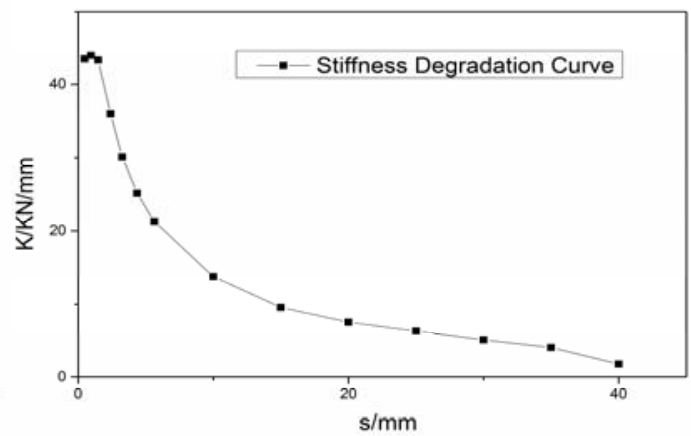

Fig.11. Stiffness degradation curve

Stiffness Degradation.Stiffness degradation curve of the structure is shown in Fig.11. The stiffness of the structure was $43.5 \mathrm{KN} / \mathrm{mm}$ at the beginning of the experiment and $1.8 \mathrm{KN} / \mathrm{mm}$ in the end. The stiffness of the structure was obviously reduced with the development of the crack. With the development of the crack, concrete beam and column replaced the walls, bearing capacity and stiffness degrade slowly at that time.

\section{Conclusions}

There is little change in resilience, displacement, acceleration of before and after the reinforcement model in the case of 6 degrees rare seismic action. The reinforcement ring beam and structural column has improved the structural integrity and stiffness. Hysteretic curve was arched and full, indict that masonry structure reinforced by concrete beams and column have considerable plastic deformation capability and energy dissipation capability. Normalized skeleton curve show that the size of the ring beams and constructional columns have a certain effect on the stiffness and the bearing capacity of the structure. The utmost load of structure was $160 \mathrm{KN}$ and utmost displacement was $40 \mathrm{~mm}$, far greater than the maximum recovery and maximum displacement under the earthquake action of 7 degrees. Therefore, after 6 degree rare earthquake, the ordinary masonry structure with no seismic fortification measures reinforced by additional concrete beams can meet the requirements of the current seismic code. 


\section{Conflict of Interests}

The authors declare that there is no conflict of interests regarding the publication of this paper.

\section{Acknowledgments}

This paper was financially supported by Beijing Natural Science Foundation (8142015) and "Undergraduate training-Approval and research of teaching reform-Experimental spot of educational reform of continuing education in colleges"(Project encoding in the college:15007-8). The authors' deeply express sincere appreciation to them.

\section{References}

[1] Yayong Wang, Wenchuan earthquake damage to the building - three level design and seismic design basic requirements, architectural structure of the journal, 2008, 29 (04): 26 33 (In Chinese)

[2] 50003-2011 GB, Masonry structure designcode[S]. Beijing: China Building Industry Press, 2011 (In Chinese)

[3]50011-2010 GB, Code for seismic design of buildings [S]. Beijing: China Building Industry Press,2011（In Chinese)

[4]JGJ116-2009, Technical specification for seismic strengthening of buildings[S]. Beijing: ChinaBuilding Industry Press, 2009（In Chinese）

[5]Yuxian Hu. Earthquake Engineering [M]:Beijing Earthquake Press, 2006 (In Chinese)

[6] Ministry of construction of the people's Republic of China, JGJ101-96, Building seismic test method, Beijing, China Standard Press, 1997（In Chinese）

[7]Dong An, Study on seismic behavior of masonry structure and its non-stationary seismic response

[D]. Tianjin University, 2013 (In Chinese)

[8] M. Tomaževič, I. Klemenc, Seismic behaviour of confined masonry walls, EarthquakeEngineering \& Structural Dynamics, 1997, 26(10):1059 1071.

[9]HuoSong; Huan Mi; Peizhen Xu, Test and detection of building structure in Beijing, People's Communications Press, 2014 (In Chinese) 